\title{
Alopecia Areata and Dry Eye
}

\author{
Dr. Yatendra Singh Chahar ${ }^{1}$, Dr. Tirupati Nath ${ }^{2}$, Dr. Yugal Rajput ${ }^{3}$
}

S.N. Medical College, Agra

\begin{abstract}
Background: There is paucity of studies reporting tear film changes and ocular surface pathologies in AA patients. Aim and Objectives: This study aims to evaluate anterior segment changes in alopecia areata patients and compare them with healthy individuals. Materials and methods: Total of 34 patients were enrolled for study with a mean age of $24.56 \pm 7.82$ years. Schirmer'stest, Tear film Break Up Time (TBUT), Tear meniscus height and Optical surface disease Index (OSDI) Questionnaire were performed to assess tear film changes. Pachymetry, keratometry and slit examination to detect any corneal involvement was also done. Results: Asymptomatic punctate lenticular opacities were found in 12 (35.3\%) cases and 2 (5.8\%) controls. Mean values of schirmer test (in mm) was $18.59 \pm 10.15$ in cases and $22.76 \pm 9.73$ in controls with $p=0.23$ while mean values of TBUT( in seconds) was $9.59 \pm 5.49$ in cases and $17.76 \pm 5.98$ in controls with $p=0.002$. Dry eye was found in $15(44.11 \%)$ cases and $6(17.6 \%)$ controls with a $p$ value 0.03 , thus statistically significant. Conclusion: Alopecia areata strikes hair and Meibomian gland and spares out lacrimal gland.
\end{abstract}

Keywords: alopecia areata, dry eye, meibomian glands

\section{Introduction}

Alopecia areata (AA) is a non cicatricial form of hair loss in a patchy, diffuse or confluent pattern on scalp or any hair bearing area of body. Autoimmunity, mainly T-cellmediated is considered to play a main role in the pathogenesis of the disease[1]. AA may affect people of any age and any sex[1],[2].

AA has been found to be associated with autoimmune diseases such as vitiligo, atopic dermatitis, lichen planus, pemphigus foliaceus, Hashimoto's thyroiditis, lupus erythematosus, Addison's disease, pernicious anaemia, diabetes mellitus, Down's syndrome[3],[4].

Studies have been done reporting ocular findings in AA patients where lenticular and retinal abnormalities have been documented[5],[6]. Relatively there is paucity of studies reporting tear film changes and ocular surface pathologies in AA patients in the literature. This study aims to evaluate ocular surface changes, tear function alteration, retinal and lenticular abnormalities in AA patients and compare them with control subjects.

\section{Materials and Methods}

A case control study of thirty four patients with AA coming to our outpatient department over a period of 4 months along with equal number of sex and age matched controls were enrolled in the study as per the consent and protocols. The patients were examined by two dermatologists and divided into single patch, multiple patches and alopecia totalis and universalis groups. The diagnosis of AA was made based on patient history, clinical findings and by biopsy in ambiguous cases. Patients using drugs like NSAIDS, diuretics, corticosteroids, immunosuppressant, phototherapy, antidepressant, anxiolytic, anticholinergic drugs or topical eye drops within the last 3 months were excluded from the study.

Schirmer's test, Tear film Break Up Time (TBUT), Tear meniscus height were performed to assess tear film stability. In this study Optical surface disease Index (OSDI)
Questionnaire was used to evaluate the symptoms and to correlate it with the results of the tests.

Pachymetry was used to measure corneal thickness. Intraocular pressure (IOP) was measured by Goldman applanation tonometry. Corneal transparency and iris pigmentary changes were examined by slit-lamp. Pupils were dilated by $1 \%$ tropicamide for detailed ophthalmoscopic lens examination.

Cases with atleast two positive results amongst these four tests (Schirmer test $<10 \mathrm{~mm}$ wet, TBUT $<10 \mathrm{~s}$, OSDI $>25$ and tear meniscus height $<1 \mathrm{~mm}$ ) were considered to have dry eye.

\section{Results}

Table 1: Demographic and ophthalmologic characteristics of patients with alopecia areata and control subjects.

\begin{tabular}{|c|c|c|c|}
\hline & Case & Control & P value \\
\hline Gender, male/female, $\mathrm{n}$ & $20 / 14$ & $18 / 16$ & 0.8 \\
\hline Mean age (years) & $24.56 \pm 7.82$ & $25.81 \pm 6.09$ & 0.61 \\
\hline $\begin{array}{c}\text { TEAR MENISCUS } \\
\text { HEIGHT (MM) }\end{array}$ & $0.751 \pm 0.414$ & $0.903 \pm 0.404$ & 0.28 \\
\hline OSDI & $26.55 \pm 10.33$ & $10.63 \pm 7.26$ & $<0.0001$ \\
\hline $\begin{array}{c}\text { PACHYMETRY (in } \\
\mu \mathrm{m})\end{array}$ & $524.69 \pm 24.09$ & $527.08 \pm 22.43$ & 0.76 \\
\hline $\begin{array}{c}\text { KERATOMETRY (in } \\
\text { dioptres) }\end{array}$ & $45.62 \pm 2.28$ & $45.34 \pm 2.37$ & 0.71 \\
\hline $\begin{array}{c}\text { Intraocular pressure, } \\
\text { mmHg, mean } \pm \text { SD }\end{array}$ & $15.06 \pm 2.40$ & $15.86 \pm 2.11$ & 0.32 \\
\hline
\end{tabular}

Table 2: TBUT findings of patients with alopecia areata and control subjects

\begin{tabular}{|c|c|c|}
\hline & Cases & Controls \\
\hline Patients with TBUT >10 seconds, $n(\%)$ & 15 & 29 \\
\hline Patients with TBUT <10 seconds, $n(\%)$ & 19 & 5 \\
\hline Mean+SD values of TBUT( in seconds) & $9.59+5.49$ & $17.76+5.98$ \\
\hline Range of TBUT (in seconds) & $26-\mathrm{Apr}$ & $30-\mathrm{Jul}$ \\
\hline Median value of TBUT (in seconds) & 9 & 18 \\
\hline P value & 0.002 & \\
\hline
\end{tabular}




\section{International Journal of Science and Research (IJSR) \\ ISSN (Online): 2319-7064}

Index Copernicus Value (2016): 79.57 | Impact Factor (2015): 6.391

Table 3: Schirmer test findings of patients with alopecia areata and control subjects

\begin{tabular}{|c|c|c|}
\hline & Cases & Controls \\
\hline Patients with $>10 \mathrm{~mm}$ wetting, $n(\%)$ & 24 & 28 \\
\hline Patients with $<10 \mathrm{~mm}$ wetting, $n(\%)$ & 10 & 6 \\
\hline Mean \pm SD values of wetting $($ in $\mathrm{mm})$ & $18.59 \pm 10.15$ & $22.76 \pm 9.73$ \\
\hline Range of Schirmer Test (in $\mathrm{mm}$ ) & Apr-33 & Aug-41 \\
\hline $\begin{array}{c}\text { Median value of Schirmer Test (in } \\
\text { mm) }\end{array}$ & 21 & 24 \\
\hline P value & 0.23 & \\
\hline
\end{tabular}

Demographic \& ocular data along with detailed TBUT and schirmer have been elaborated in Table 1, 2 and 3 respectively. Of the patients with alopecia areata, 8 (23.5\%) patients had a single patch, $25(73.5 \%)$ patients had multiple patches and $1(3 \%)$ patient had alopecia universalis. 10 (29.4\%) patients had madarosis and $6(17.6 \%)$ had eyelash involvement. There was no significant association between ocular findings and type of alopecia or extent of involvement. ( $\mathrm{p}$ value $>0.05$ ).

Asymptomatic punctate lenticular opacities were found in 12 $(35.3 \%)$ cases and $2(5.8 \%)$ control patients with a $p$ value $<0.005$, thus is considered highly statistically significant.

Dry eye was found in $15(44.11 \%)$ cases as compared to 6 (17.6\%) controls with a p value 0.03 , thus statistically significant.

\section{Discussion}

Ocular alterations are a common manifestation in alopecia areata with the lenticular changes being a common one ranging from punctate opacities to cataract. In our study we found that lenticular opacities were found in $35.3 \%$ cases as compared to $5.8 \%$ in controls $(\mathrm{p}<0.005)$.Similar observations have been reported by Recupero et al[7] and Tosti[6] et al who found lenticular changes in $78 \%$ and $51 \%$ cases of alopecia areata as compared to $27 \%$ and $3 \%$ in control groups respectively while Summerly et al[8] and Bianchi et al[9] did not found any statistically significant association of lenticular opacities in alopecia areata cases versus controls. Pandhi et al[10] on examining 83 AA patients found that 20 patients had punctate opacities, 6 and 4 patients had posterior and anterior subcapsular cataract respectively. This differences in results can be as alopecia areata has been found to be associated with atopic dermatitis in which anterior subcapsular cataract is found or due to long term steroid use to treat AA which can cause posterior subcapsular cataract. In our study we did not found any cataract because patients were relatively young but found punctate opacities. Exact data regarding previous use of steroid could not be obtained.

The mean keratometric (in dioptres) and pachymetric findings (in $\mu \mathrm{m}$ ) in our study are $45.62 \pm 2.28$ and $524.69 \pm$ 24.09 in AA cases versus $45.34 \pm 2.37$ and $527.08 \pm 22.4 \overline{3}$ in control group, respectively. Similar findings have been reported by Esmer et al[11] in alopecia areata patients, where he noticed keratometric findings to be in a range of 43-44 dioptres and corneal thickness of 536-538 $\mu \mathrm{m}$ in both cases and control groups. No keratoconus was seen in our study as it is seen in atopic dermatitis associated with alopecia areata.

In our study we found that the mean OSDI was $26.55 \pm 10.33$ in the cases while it was $10.63 \pm 7.26$ in the controls and the difference is statistically significant. Similar findings have been reported by Ergin et al[12] found OSDI of $30.92 \pm$ 19.26 in cases and $4.43 \pm 4.19$ in controls. Similarly Ergin et al also reported statistically significant change in TBUT $7.94 \pm 3.49$ seconds in cases and $13.5 \pm 2.65$ seconds in controls, likewise as seen in our study.

In our study no statistically significant difference was found in IOP in cases and controls and similar findings have been reported by Esmer et al[11] with an IOP of $12.17 \pm 2.12$ and $11.89 \pm 2.08$ in right eye of cases and controls, respectively. Schirmer test findings were statistically insignificant in our study and similarly Ergin et al[12] found $13.72+4.47 \mathrm{~mm}$ wetting in cases and $13.05 \pm 2.7 \mathrm{~mm}$ wetting in controls with $\mathrm{p}=0.55$. Esmer et al[11] also found $12.17 \pm 2.12 \mathrm{~mm}$ wetting in cases and $11.89 \pm 2.08 \mathrm{~mm}$ in controls, $\mathrm{p}=0.663$ in right eye and similar findings in other eye as well.

Prevalence of dry eye worldwide ranges from 5\% to $35 \%$ and in India it is $29.25 \%$ as per Ocular Surface Disease Index (OSDI) data[13] and $18.4 \%$ as per another hospital based Indian study[14]. We noticed dry eye in $15(44.11 \%)$ cases as compared to $6(17.6 \%)$ controls with a p value 0.03 .

This variation in the prevalence of dry eye may be due to the geographical, climatic and humidity alteration reigning in various places.

This wide disparity in results can be attributed to the fact as there is no standardization of objective tests, dry eye questionnaires and dry eye diagnostic criteria.

\section{Conclusion}

Studies with eye findings in AA patients are limited and rarely include detailed anterior segment examination which have been performed in the present study. Presence of normal schirmer test with abnormal TBUT indicate that meibomian gland are the target of $\mathrm{T}$ lymphocytes with lacrimal glands being spared leading to dry eye. Due to smaller sample size of this study individual findings may differ, thus larger randomised trials are required. Owing to the above findings it can be stated that alopecia areata strikes hair evidently while it hit eyes mutely.

\section{Conflict of interest- NIL}

Financial Support- NIL

\section{References}

[1] Hordinsky M, Ericson M. Autoimmunity: Alpecia areata. J Investig Dermatol Symp Proc 2004;9:73-8.

[2] Mac Donald Hull SP,Wood M L, Hutchinson P E, Saidden M, Messenger A G. Guidelines for management of AA. British Journal of Dermatology 2003; 149:692-9. 


\section{International Journal of Science and Research (IJSR) \\ ISSN (Online): 2319-7064}

Index Copernicus Value (2016): 79.57 | Impact Factor (2015): 6.391

[3] Muller SA, Winkelmann RK. Alopecia areata. Arch Dermatol 1963;88:290-97.

[4] Brenner R. Coincidences of alopecia areata, Vitiligo, Onychodystrophy, localized scleroderma and lichen planus. Dermatologica 1979;159:356-8.

[5] Tosti A, Colombati S, De Padova MP, et al. Retinal pigment epithelium function in alopecia areata. J Invest Dermatol 1986;86:553-5.

[6] Tosti A, Colombati S, Caponeri GM, et al. Ocular abnormalities occurring with alopecia areata. Dermatologica 1985;170:69.

[7] Recupero SM, Abdolrahimzadeh S, de Dominicis M, et al. Ocular alterations in alopecia areata. Eye (Lond) 1999;13:643-6.

[8] Summerly R, Watson DM, Monckton PW. Alopecia areata and cataract. Arch Dermatol 1966;93:411-12.

[9] Bianchi PE, Malvezzi F, Stringa M, Orecchia G. Lens opacities occurring in alopecia areata. Ann OttalmolClinOcul 1988;114:129-32.

[10] Pandhi D, Singal A, Gupta R, Das G. Ocular alterations in patients of alopecia areata. J Dermatol.2009;36:2628.

[11] Esmer O, Karadag R, Cakici O, Bilgili SG, Demircan YT, Bayramlar $\mathrm{H}$ et al Ocular findings in patients with alopecia areata. Int J Dermatol. 2016;55:814-18.

[12]Ergin C, Acar M, Kaya Akış H, Gönül M, Gürdal C. Ocular findings in alopecia areata. Int $\mathrm{J}$ Dermatol. 2015;54:1315-8.

[13] Bhatnagar KR, Sapovadia A, Gupta D, Kumar P, Jasani H. Dry eye syndrome: A rising occupational hazard in tropical countries. Med J DY PatilUniv 2014;7:13-8.

[14] Sahai A, Malik P. Dry Eye: Prevalence and Attributable Risk Factors in a Hospital-Based Population. Indian J Ophthalmol 2005;53:87-91. 